\title{
Emotional Disturbances Expressed by Deaf Patients: Affective Deaf Syndrome
}

\author{
Madeleine ET Zöller* and Trevor Archer
}

Department of Psychology, University of Gothenburg, Sweden

\begin{abstract}
Structured assessment of affective mood and mental distress in deaf and hard-of-hearing individuals is difficult for various reasons. The aim of this paper is to examine the complex interaction between self-rated affective mood as well as the combined double burden of affective psychiatric disorders and deafness/hard-of-hearing, this interaction system has been termed the Affective Deaf Syndrome. Deaf and hard-of-hearing psychiatric polyclinic patients at a University Hospital in Sweden $(n=52)$ were compared to healthy individuals $(n=116)$. The Positive Affect and Negative Affect Scale, Rosenberg's Self-esteem Scale, the Stress and Energy questionnaire and a Background \& Health Questionnaire were used. Our results clarified some issues of the emotional disturbances among the patient group with the following results. Firstly, the communication between family members was hindered due to a high rate of non-fluent sign communication $(86 \%)$ within the families of the patients. Only few $(10 \%)$ of the patients were found to have fluent Swedish language skills. Secondly, self-esteem was found to predict positive affective mood for patients $(p<.01)$ and for controls $(p<.001)$ although the patients had less self-esteem. Positive self-esteem is identified as a protective factor. Thirdly, ANOVA results indicated significant differences between patients and the healthy control group in self-rated stress $(p<.001)$, analgesics $(p<.001)$ and self-rated energy $(p<.001)$. The conclusions from regression analyses of the patient group were that analgesics may be seen as a predisposing factor for the Affective Deaf Syndrome (ADS) and was identified as a key attribute for the patients at risk. Stress was positively related to sleep disturbance and analgesics. Further, suggestions on how to enhance the treatment quality of the patient group are presented.
\end{abstract}

Keywords: Affective mood; Affective deaf syndrome; Deaf and hard-of-hearing; Psychiatric diagnoses; Self-esteem; Energy; Stress; Analgesics

\section{Emotional Disturbances Expressed by Deaf Patients: Affective Deaf Syndrome}

Deafness and hard-of-hearing is not only a problem of hearing loss. Although deaf patients enter psychological and psychiatric treatment with the same disorders as hearing patients, there are special circumstances that are created by their cultural background and position in society [1-3]. The fact that the Deaf and hard-of-hearing have communication problems with family and society, because of not being able to communicate with the dominant language of the society, may lead to isolation and further contribute to the heavy burden of the disability. Sign language interpreters in mental health settings face extreme linguistic and cultural difficulties in interpreting basic everyday language. This difficulty is even greater when it comes to interpreting in mental health settings. For special issues and concerns see e.g. [4].

The interrelationship between chronic physical illness, depression or depressive symptoms has been associated with individuals' cognitive-emotional behavioral profiles that are linked to sets of psychosocial resources determining health outcomes [5-9]. Depression is characterized by low levels of self-esteem, low levels and/or unstable self-esteem may offer an enduring vulnerability factor for depression [10-15]. Stress and/or stressful situations may accompany many aspects of an individual's everyday life. Stress influences individual's psychological and physical health negatively [16]. Individuals' experience of stress are highly subjective with some individuals experiencing more predispositions than others to appraise situations as threatening or problematic, thereby at risk for psychosomatic illhealth, including cognitive difficulties and sleep problems [17]. This paper examines key issues for the combined mental distress of hearing disability, psychiatric disorders and affective mood.

Affective mood depends on both positive affect (PA) as well as negative affect (NA). Both PA and NA may possess explanatory value despite these scales being correlated with different factors [18]. The two dimensions are also measures of anxiety and depression - anxiety is a state of high NA whereas depression is a mixed state of high NA and low PA [19]. PA and NA not only express temperamental dispositions but are also complementary to extraversion and neuroticism [20]. It appears that both PA and NA influence individuals' relations to stressors, situations associated with stress and the experience of stress [21,22]. It is possible that the 'affective profile' of individuals predisposes them to confront stressful situations with different propensities.

Affective personality self-reported data concerning stress may be associated with affective states [23]. Most studies use PA and NA to define emotional state rather than a 'trait like' temperament [24]. It has been found repeatedly that NA reflects expressions of affect, such as anger, contempt, guilt, shame, fear and depressiveness, that appear to present relatively stable personality characteristics [25-27] whereas PA expresses enthusiasm, activity, control and feelings of duty, associated with a positive attitude, both over time and varying

*Corresponding author: Zoller M, Department of Psychology, University of Gothenburg, Sweden, Tel: +46-707-25-6447; E-mail: madeleine.zoller@psy.gu.se

Received: December 01, 2015; Accepted: December 05, 2015; Published: December 12, 2015

Citation:Zöller MET, Archer T (2015) Emotional Disturbances Expressed by Deaf Patients: Affective Deaf Syndrome. Clin Exp Psychol 2: 109. doi:10.4172/24712701.1000109

Copyright: @ 2015 Zöller MET, et al. This is an open-access article distributed under the terms of the Creative Commons Attribution License, which permits unrestricted use, distribution, and reproduction in any medium, provided the original author and source are credited. 
circumstance $[28,29]$. Individuals characterized by high levels of PA experience a greater appreciation of life, more security, generally show more self-confidence [30,31], more social relations and assertiveness, greater satisfaction of friends, and are often described as passionate, happy, energetic and alert [32,33]. On the other hand, those individuals characterized by NA experience greater stress, anxiety and strain under a wide range of circumstances and events of which they experience limited, if any, control. Currently, the concept of affective personality has been replaced by the more applicable notion of affective profiles [34]. There has been observed quite regularly from data not including psychiatric patients that stress could be predicted from negative affect [35-38].

The present study built on our earlier studies of affective mood, stress and self-esteem at the Psychological Institution at Göteborg University and Sahlgrenska University Hospital on affective personality. It includes psychiatrically ill patients who fulfilled the psychiatric diagnostic criteria (DSM IV-R and ICD-10) for major depressive disorder 54\%, anxiety disorder $37 \%$ and a mixed group $9 \%$ including bulimia nervosa, polymorph psychosis and Attention Deficit/Hyperactivity disorder (ADHD). Eighty-three \% of the patients also fulfilled the criteria for personality disorder with mainly borderline diagnoses according to DIP-Q [39]. The study clearly indicated that patients who have had a psychiatric diagnosis differ from healthy controls with regard to PA, NA, depression, compulsion, anxiety and personality traits (DIP-Q), as well as stress, energy, and optimism. The patient group expressed lower PA, energy, and optimism compared to healthy controls. The clinical implications of the findings indicate clear associations between stress, affect, and mood state despite the modulation through pharmacotherapeutic agents. The disadvantage is more serious in the patient group. These findings are consistent with those obtained in earlier studies wherein patients presenting Neurofibromatosis type 1 together with dysthymia/depression at a similar level of severity were investigated. Mood states and affect are associated with serotonergic systems [40-42]. This renders it understandable that the findings in the two groups are similar.

In order to treat the patients, it is important to be able to predict stressful situations. The ability of predicting stress both in male and female psychiatric patients as well as in healthy volunteers was studied [40]. The results indicated that stress could be predicted from negative affect and counter-predicted by positive affect. A conclusive gender effect was found in the control group and pertained to anxiety where the female participants evidenced more than twice as much anxiety as the males. Independent of gender, patients otherwise showed markedly greater negative affect and anxiety than the healthy control group, as well as markedly lower levels of positive affect and optimism.

Considerable evidence suggests that self-esteem may influence individuals' perceptions and cognitive appraisals of and responses to a multitude of events and situations, such as occupation, examinations, illness, stress, chronic pain etc. [47-53]. Self-esteem may be crucial to ensuring psychosocial well-being through the modulation of personal aspirations, goals, motives and social interactions [54]. It has been linked to better adjustment, lower depression, and less helplessness in individuals presenting a variety of health problems [55-57]. Individuals expressing high levels of self-esteem seem to possess both belief and expectancy regarding their own merits, abilities, strengths and competence [58-60]. In inregard to this, optimism has been shown to be an intrapersonal resource that may counteract the impact of negative events linked to lower levels of depression, greater well-being, more health benefits and positive outcome over a wide range of studies [6165]. Individuals with optimistic expectancies express positive outlooks, even under difficult circumstances [66], and they possess numerous active coping strategies [67-70]. Earlier studies of affective mood and psychiatric illness including patients with deafness and /or hard-ofhearing have reported conflicting results. For example [71] reported that among deaf psychiatric ill persons as much as $50 \%$ of the precipitant causes of the patients revolved around early traumatic physical injuries, operations, or fear of separation from significant relationships. In what they termed "traumatic injury," Grinker et al. noted that $21 \%$ of patients displayed disturbed behavior. In a more recent study [72] showed a broader range of diagnoses than in past studies, with posttraumatic stress disorder being the most common diagnosis. Compared with hearing patients, the deaf patients were less likely to be diagnosed with a psychotic or substance abuse or disorder and more likely to be diagnosed with a mood, anxiety, personality, or developmental disorder. An important finding [72] was that $75 \%$ of deaf individuals fell into the non-fluent range of communication in American Sign Language. Mood disorders and substance abuse were diagnosed infrequently in past research and traumata and their sequelae have earlier hardly been addressed at all [73]. Only in recent years, have special psychiatric units with staff trained in the use of sign language contributed to research on the deaf and hard-of hearing, this might be a reason for divergent results from earlier studies. The sign language being a different kind of language, using pictures and not words, cannot be translated into spoken language without problems. This specific problem is well known in the deaf culture and must be taken into account [74].

\section{Aims of the Study}

This study aims to investigate emotional disturbances by deaf and hard-of-hearing patients as expressed in the Affective Deaf Syndrome. This syndrome consists of complex interactions of communication, affective mood and psychiatric disturbances. The present study has three aims. The first aim is to clarify the level of communication problems. The second aim is to study the differences in affective mood between a patient group with deaf/hard-or-hearing patients and a healthy control group. The third aim is to identify predisposing and protective factors in the patient group by identifying key attributes for the identification of patients at risk.

\section{Method}

\section{Participants and procedures}

Psychiatric patients with severe hearing impairment and deafness were recruited from the University Hospital in Gothenburg. The diagnostic assessments were all performed by a psychiatrist assigned to the Deaf Unit. The specialist team consisted of a psychiatric consultant, a psychologist, an occupational therapist, a social counselor and a specialist nurse and it has many years of established expertise in clinical treatment of deaf people. The team all worked with interpreters using the Swedish Sign Language (SSL), who usually served at the clinical team specializing in psychiatric care of deaf people and thus were familiar with the patients and the complex issues and concerns in interpreting in mental health settings. The procedure could vary from patient to patient where most of the patients needing more than one session to fill in the questionnaires. There was a problem presenting the questions in a way that was understood by patients not knowing the Swedish language and only having rudimentary knowledge by the SSL. The patients had the possibility to use text message if they had any further questions or wanted to interrupt the participation for the procedure of the study. Patients with severe mental retardations were excluded from the study. Except for two patients all the patients were willing to take part in the study. The data were collected during a 12-month period from August 
2014 until August 2015. The group consisted of 52 patients, 33 deaf and 19 hard-of-hearing (including a few relatives who also received treatment at the unit), the group consisted of 10 men and 42 women with a mean age of 42.63 years $(S D=12.74$; range $=21-71)$. Psychiatric diagnostic system used was (DSM-5 and ICD-11).

A healthy control group was recruited from the same socioeconomic area as the patients. The healthy volunteers were not paid for their participation. The group had to sign an agreement of participation and that they had received information that they could stop the participation of the study at any moment. The number of healthy controls were 116 participants, 41 men and 75 women, with a mean age of 46.48 years $(S D=13.76$; range $19-75)$. Each participant was asked to complete a battery of psychometric test instrument as well as a Background and Health Questionnaire.

\section{Ethical considerations}

The ethics protocol of Sahlgrenska University Hospital, Gothenburg was applied and maintained. The patients were in their habitual psychiatric state. Most had been treated by medication and psychotherapy for some period before the study. Their hearing loss ranged from very severe to total loss of hearing. The SSL was used when needed and was offered by trained translators who also outside the study helped the same patients with interpretation.

\section{Assessment tools}

A Background and Health Questionnaire including age, gender, partnership, number of children and age of children, years of education after the obligatory nine year education, smoking and drinking habits, pain, sleeping problems, physical exercise, television hours/ day, percentage of sedentary work, self-evaluation of general health, use of mood-enhancing drugs and analgesics, length, weight and waist measurement were completed according to the description and procedure outlined in[82].

The DSM-5 (American Psychiatric Association diagnostic and Statistical Manual of Mental Disorders, 2013) [78] is the standard classification system of mental health disorders used by professionals for research in Sweden and the International Classification of Diseases Revision 11 (ICD 11), system is used in clinical praxis in Sweden were applied in the study.

\section{Positive Affect Negative and Affect Scale (PANAS)}

The instrument provides a self-estimation of "affect", both positive and negative. It consists of 10 adjectives for the Negative Affect (NA) dimension (Negative affect: Cronbach's $\alpha=.83$ ) and 10 adjectives for the Positive Affect (PA) dimension (Positive affect: Cronbach's $\alpha=$ .88). The adjectives describe feelings (affect) according to Watson [26] Respondents give their estimates on a 5-point scale (from "not at all" to "very much"). The 10 -item positive affect scale includes adjectives such as strong, proud, and interested. The 10 -item negative affect scale includes adjectives as afraid, ashamed, and nervous. Others [90] have shown that there does not exist any significant correlation between the extent of positive and negative effectiveness, which implies that a 'divergent validity' appears to be the case. Currently, the notion of affective profiles has been applied to describe participants' expression of mood state [75-77, 79-80]. The internal consistency for Negative affect was $=.88$ (Chronbach's $\alpha)$, Positive affect $=.88$. Affective mood defined as (Positive affect/ Negative affect) ${ }^{\star} 100=.88$ (Chronbach's $\alpha$ ).

Stress and Energy (SE)
The instrument is a self-estimation scale that assesses individual's experience of their own stress and energy. The test is divided into two sub-scales that express each participant's level of mood in the two dimensions: "experienced stress" and "experienced energy". Response alternatives are ordered within six-graded scales that extend from $0=$ not at all to $5=$ very much. The instrument has been validated through studies concerning occupational burdens and pressures [81-85]. The SE-scale has been constructed from the earlier used checklist, Mood Adjective Check-List which was modified by [86-89] reduced the list to 12 adjectives in the two dimensions, stress and energy, which provides the latest version applied here. The internal consistency was found to be stress $=.90$ (Chronbach's $\alpha)$ and energy $=.75$ (Chronbach's $\alpha)$.

\section{Rosenberg's Self-esteem Scale (SES)}

The Self Esteem Scale is comprised of 10 items where each item is rated on a five-point scale form 0 (does not agree) to 5 (completely agrees). This scale is constructed after the Tennessee Self Concept Scale. The SES instrument is a self-estimation, 10-item questionnaire which has been constructed to measure the extent to which individuals consider themselves "sufficiently functional", particularly in adolescents and young adults. Self-esteem is measured using ten items (statements, each item rated on a four point Likert scale) concerned with feelings about oneself and one's attitude towards one's resources, relations to others and achievements, whereby half of the statements express positive aspects about self and half express negative aspects. The participants were required to respond with the number that they considered to fit the degree to which they agreed with the statement or disagreed with the statement, whereby 1 = "agree completely" and 4 =" disagree completely". For example, statements like "I can do things as well as anybody else", or "I wish that I had more respect for myself", or "On the whole I am satisfied with myself". The reliability of the test was described to be .86 and it was only weakly correlated with age, education, and general intellectual performance (Fits WHO. Manual. Tennessee Self Concept Scale. Nashville (Tenn.): Counselor Recording and Tests, 1965). The internal consistency in our study was .85 (Chronbach's $\alpha$ ).

\section{Statistical Analyses}

Data were analyzed using SPSS version 20 software. Pillai's Multivariate Analysis of Variance (MANOVA) was applied with type of group and gender as independent variables and with stress, energy, and number of cigarettes/day, pain, analgesics, television, self-esteem and affective mood as dependent variables, a correlation analysis was performed and one-way ANOVA was performed likewise. A linear regression analysis was performed to examine to which extent affective mood may be predicted from the dependent variables. A nonparametric chi-square was carried out to compare the patient population and the healthy controls to compare the patient population and the controls with regard to the dependent variables.

\section{Results}

Psychiatric diagnostic system used was (DSM-5 and ICD-11). The patients fulfilled the criterion for the following psychiatric conditions: Depressive disorders (F32 and F33; DSM 296) $=43 \%$, Anxiety disorders F 41, DSM 300) $=33 \%$, Trauma- and Stressor-Related disorders (F43; DSM 308, DSM 309) = 33\%, Attention-Deficit/Hyperactivity disorder (F90; DSM 314) $=21,4 \%$, Obsession-Compulsive disorder 300.3 (F42) $=12 \%$, Schizotypal Personality disorder (F21, F22; DSM 301., DSM $297)=7 \%$, Autism Spectrum Disorder (F84; DSM 299) was observed in our material in $21 \%$ of the patient group. Personality disorder Cluster 
Citation: Zöller MET, Archer T (2015) Emotional Disturbances Expressed by Deaf Patients: Affective Deaf Syndrome. Clin Exp Psychol 2: 109. doi:10.4172/2471-2701.1000109

Page 4 of 8

$\mathrm{B}=5 \%$, Substance-Related and Addictive disorders $(\mathrm{F} 10 ; 303.00)=5 \%$. Forty-two \% of the patients (Table 1) fulfilled more than one diagnosis. Most common was the combination of Depressive disorder combined with Anxiety disorder and/or Trauma-and Stressor-Related disorders.

Most of the patients $86 \%$ had no deaf parent, and $74 \%$ of the patients had no deaf siblings or relatives. Ten $\%$ of the deaf patients were found to have fluent Swedish language skills. Adding to this problem, only $14 \%$ of family communication was with fluent sign and most of family communication-was with speech, writing, and gesture, and 12 $\%$ with some sign. Support may also be difficult to give from the side of the family because as many as $42 \%$ of the patients fulfilled at least two psychiatric diagnoses. Type of deafness: deaf $=63,5 \%$, and hardof-hearing $=36,5 \%$. Etiology of deafness: unknown $=38,0 \%$, hereditary $=30,9 \%$, Rubella $=16,7 \%$, Meningitis $=2,4 \%$, prematurity $=2,4 \%$, infection $=4,8 \%$ and other $=4,8 \%$. Hearing status of parents: none deaf parents $=85,7 \%$, one deaf $4,8=\%$ and two deaf parents $=9,5 \%$. Hearing status of siblings and relatives: one deaf $=4,8 \%$ and more than one deaf $=21,4 \%$. Family communications: Speech, writing, and gesture $=73,8$ $\%$, some sign $=11,9 \%$ and fluent sign $=14,3 \%$.

Pillai's multivariate analysis of variance (MANOVA) (2x2 factorial design) was applied. One way analyses of variance (ANOVAs) indicated that there was a significant influence of psychiatric disease (for patients and controls) on PA, NA, self-esteem, energy, stress, number of cigarettes/day, pain, analgesics, hours of television, and Affective Mood. Table 2 provides the results of the ANOVAs showing means, and standard deviations of the different items for patients and controls.

Table 3 provides the results of correlation analyses (Pearsons' $r$ ) performed between positive affect, negative affect, self-esteem, energy, stress, number of cigarettes/day, sleep, physical activity, analgesics, pain and hours of television/day. Positive affect produced significant positive correlations with self-esteem and energy, and a significant negative correlation with stress and pain. Negative affect produced significant negative correlations with self-esteem and energy but significant positive significance with sleeping problems and analgesics. Self-esteem produced positive significant correlations with energy and significant negative correlations with stress and sleeping problems. Energy produced negative significant correlation with sleeping problems and pain. Stress produced positive significant correlations with sleeping problems and analgesics. Sleeping problems produced significant negative correlation with hours of television. Analgesics produced significant positive correlation with pain.

\section{Regression analysis}

Patient group (Table 4). In order to assess the extent to which affective mood may predict the result outcome pertaining to the variables estimated in self-evaluation, analgesics, hours of television/ day, pain, problems of sleep, stress and energy, a regression analysis was performed with each of the former as independent variables and affective mood as dependent variable. The analysis indicated that affective $\operatorname{mood}\left(F(8,43)=6.68, p<0.001\right.$, adj. $\left.R^{2}=0.47\right)$ could be predicted from high self-evaluation whereas analgesics were counterpredictive for affective mood.

Healthy volunteers (Table 5). In order to assess the extent to which affective mood may predict the result outcome to the variables estimated in Self-esteem, analgesics, hours of television/day, pain, problems of sleep, stress and energy, a regression analysis was performed with each of the former as independent variables and affective mood as dependent variable. The analysis indicated that affective $\operatorname{mood}(F(8,107)=22.70$, $p<0.001$, adj. $\left.R^{2}=0.60\right)$ could be predicted from high Self-esteem and

\begin{tabular}{|c|c|c|c|c|}
\hline & \multicolumn{2}{|c|}{ Patients } & \multicolumn{2}{|c|}{ Healthy Controls } \\
\hline & $\begin{array}{c}\text { Men } \\
(n=10)\end{array}$ & $\begin{array}{c}\text { Women } \\
(n=42)\end{array}$ & $\begin{array}{c}\text { Men } \\
(n=41)\end{array}$ & $\begin{array}{c}\text { Women } \\
(n=75)\end{array}$ \\
\hline $\begin{array}{c}\text { Stress } \\
{\left[F_{(3,165)}=7.53, \mathrm{p}<0.001\right]}\end{array}$ & $2.00 \pm 1.25$ & $\begin{array}{c}2.68 \pm 1.10 \\
A^{\star \star \star}\end{array}$ & $\begin{array}{c}1.62 \pm 0.84 \\
C^{\star \star *}\end{array}$ & $1.84 \pm 1.19$ \\
\hline $\begin{array}{c}\text { Energy } \\
{\left[F_{(3,165)}=11.46,\right.} \\
p<0.001]\end{array}$ & $\begin{array}{c}2.70 \pm 0.85 \\
F^{\star *}\end{array}$ & $\begin{array}{c}2.78 \pm 0.80 \\
A^{\star \star \star}\end{array}$ & $2.99 \pm 0.89$ & $\begin{array}{c}3.55 \pm 0.70 \\
E^{\star *}\end{array}$ \\
\hline $\begin{array}{c}\text { Cigarettes } \\
{\left[F_{(3,165)}=2.39 \mathrm{~ns}\right.}\end{array}$ & $3.70 \pm 5.56$ & $1.79 \pm 4.18$ & $0.71 \pm 2.36$ & $0.89 \pm 3.54$ \\
\hline$\left[F_{(3,165)}=5.22, \mathrm{p}<0.01\right]$ & $3.00 \pm 1.16$ & $\begin{array}{c}3.57 \pm 1.21 \\
\mathrm{~B}^{\star *}\end{array}$ & $\begin{array}{c}2.66 \pm 1.35 \\
D^{\star *}\end{array}$ & $2.68 \pm 1.25$ \\
\hline $\begin{array}{c}\text { Analgesics } \\
{\left[F_{(3,165)}=7.86, \mathrm{p}<0.001\right]}\end{array}$ & $2.00 \pm 1.06$ & $\begin{array}{c}2.50 \pm 1.40 \\
\mathrm{~B}^{\star \star}\end{array}$ & $\begin{array}{c}1.46 \pm 0.90 \\
C^{* * *}\end{array}$ & $1.81 \pm 0.88$ \\
\hline $\begin{array}{c}\text { Television } \\
{\left[F_{(3,165)}=7.00, \mathrm{p}<0.001\right]}\end{array}$ & $2.40 \pm 1.27$ & $\begin{array}{c}2.40 \pm 1.21 \\
\mathrm{~B}^{\star *}\end{array}$ & $\begin{array}{c}3.17 \pm 0.86 \\
D^{* *}\end{array}$ & $3.13 \pm 0.08$ \\
\hline $\begin{array}{l}\text { Self-esteem } \\
{\left[\begin{array}{c}F_{(3,165)}=14.20 \\
\mathrm{p}<0.001]\end{array}\right.}\end{array}$ & $\begin{array}{c}2.76 \pm 0.61 \\
G^{*}\end{array}$ & $\begin{array}{c}2.63 \pm 0.62 \\
A^{\star \star *}\end{array}$ & $\begin{array}{c}3.20 \pm 0.48 \\
C^{* * *}\end{array}$ & $3.23 \pm 0.46$ \\
\hline $\begin{array}{l}\text { Affective mood } \\
{\left[F_{(3,165)}=15.68\right.} \\
p<0.001]\end{array}$ & $\begin{array}{l}155.05 \pm \\
50.63\end{array}$ & $\begin{array}{c}129.35 \pm \\
53.30 \\
A^{* * *}\end{array}$ & $\begin{array}{c}210.95 \pm \\
64.65 \\
C^{\star \star *}\end{array}$ & $\begin{array}{c}215.02 \pm \\
78.21\end{array}$ \\
\hline
\end{tabular}

Table 1: Descriptive Statistics for Patients and Control Groups distributed in relation to Gender. Means and SD $( \pm)$ Self-reported stress, energy, number of cigarettes/ day, pain, use of analgesics, number of hours of television/day, self-esteem and affective Mood. Pillai's Trace. Between male and female groups significances ${ }^{* *} p<0.01,{ }^{* * *} p<0.001, n s=$ non-significant

$A^{* * *} p<0.001$ between female patients and female controls, $B^{* * *} p<0.01$ between female patients and female controls, $C^{* * *} p<0.001$ between male controls and female patients, $D^{* *} p<0.01$ between male controls and female patients, $E^{\star *}$ $p<0.01$ between female and male controls, $F^{* *} p<0.01$ between male patients and female controls, $G^{*} p<0.05$ between male patients and female controls.

\begin{tabular}{|l|l|l|l|}
\hline Measure & & $\begin{array}{l}\text { Patients } \\
\text { M/SD }(\boldsymbol{n}=\mathbf{5 2})\end{array}$ & $\begin{array}{l}\text { Controls } \\
\text { M/SD }(\boldsymbol{n}=116)\end{array}$ \\
\hline Positive Affect & {$[F(1,167)=10.55, \mathrm{p}<0.01]$} & $3.08 \pm 0.76$ & $3.41 \pm 0.52$ \\
\hline Negative Affect & {$[F(1,167)=43.82, \mathrm{p}<0.001]$} & $2.55 \pm 0.86$ & $1.79 \pm 0.59$ \\
\hline Self-esteem & {$[F(1,167)=42.34, \mathrm{p}<0.001]$} & $2.66 \pm 0.61$ & $3.22 \pm 0.46$ \\
\hline Energy & {$[F(1,167)=19.06, \mathrm{p}<0.001]$} & $2.76 \pm 0.80$ & $3.35 \pm 0.82$ \\
\hline Stress & {$[F(1,167)=18.14, \mathrm{p}<0.001]$} & $2.55 \pm 1.15$ & $1.77 \pm 1.08$ \\
\hline Cigarettes & {$[F(1,167)=4.83, \mathrm{p}<0.05]$} & $2.15 \pm 4.48$ & $0.83 \pm 3.16$ \\
\hline Pain & {$[F(1,167)=14.03, \mathrm{p}<0.001]$} & $3.46 \pm 1.21$ & $2.67 \pm 1.28$ \\
\hline Analgesics & {$[F(1,167)=16.40, \mathrm{p}<0.001]$} & $2.40 \pm 1.35$ & $1.69 \pm 0.90$ \\
\hline Television & {$[F(1,167)=21.21, \mathrm{p}<0.001]$} & $2.40 \pm 1.21$ & $3.15 \pm 0.84$ \\
Self-esteem & {$[F(1,167)=42.34, \mathrm{p}<0.001]$} & $2.66 \pm 0.61$ & $3.21 \pm 0.46$ \\
\hline Affective Mood & {$[F(1,167)=44.88, \mathrm{p}<0.001]$} & 134.29 & $\mathbf{5} 210.40 \pm 73.69$ \\
\hline
\end{tabular}

Table 2: ANOVA Results and Descriptive Statistics for Patients and Control Groups energy whereas stress was counter-predictive for affective mood.

\section{Discussion}

The primary aim of the current study was to investigate affective mood in deaf and hard-or hearing psychiatric patients at an out-patient unit at the University Hospital Sahlgrenska, in Gothenburg, Sweden and in a healthy control group. The aim was first to clarify the level of communication problems within of patient group. The second aim was to study the affective mood in the two groups and to compare differences. The third aim dealt with further studies of the patient group. We aimed at clarifying the complex interaction of self-rated affective mood and the double burden of psychiatric illness diagnosed together with deafness or severely hearing loss. On the basis of regression analyses, we intended to identify predisposing and protective factors. This aim included identifying key attributes for the identification of patients at risk. The hope was to find ways to help patients to overcome the affective problems they meet by applying the results in clinical 
Citation: Zöller MET, Archer T (2015) Emotional Disturbances Expressed by Deaf Patients: Affective Deaf Syndrome. Clin Exp Psychol 2: 109. doi:10.4172/2471-2701.1000109

Page 5 of 8

\begin{tabular}{|c|c|c|c|c|c|c|c|c|c|c|c|}
\hline Variables & PA & NA & SES & Energy & Stress & Cig. & Sleep & Ph. A. & Analg. & Pain & TV \\
\hline PA & 1.00 & & & & & & & & & & \\
\hline NA & -0.12 & 1.00 & & & & & & & & & \\
\hline SES & $0.44^{* *}$ & $-0.51^{\star *}$ & 1.00 & & & & & & & & \\
\hline Energ. & $0.57^{* *}$ & $-0.32^{*}$ & $0.53^{\star *}$ & 1.00 & & & & & & & \\
\hline Stress & $-0.39^{* *}$ & 0.26 & $-0.45^{\star *}$ & -0.22 & 1.00 & & & & & & \\
\hline Cig. & 0.05 & -0.16 & 0.27 & -0.08 & -0.25 & 1.00 & & & & & \\
\hline Sleep & -0.12 & $0.32^{*}$ & $-0.40^{* *}$ & $-0.28^{*}$ & $0.29^{*}$ & -0.1 & 1.00 & & & & \\
\hline Ph. A. & 0.02 & 0.11 & -0.25 & -0.14 & 0.25 & 0.10 & -0.03 & 1.00 & & & \\
\hline Analg. & -0.04 & $0.47^{* *}$ & -0.07 & -0.10 & $0.35^{\star}$ & -0.06 & 0.25 & 0.01 & 1.00 & & \\
\hline Pain & $-0.34^{*}$ & 0.17 & -0.16 & $-0.36^{* *}$ & 0.27 & -0.18 & 0.22 & -0.04 & $0.34^{*}$ & 1.00 & \\
\hline TV & -0.04 & -0.16 & 0.12 & 0.16 & -0.03 & -0.10 & $-0.30^{*}$ & 0.07 & -0.14 & -0.20 & 1.00 \\
\hline
\end{tabular}

$\mathrm{PA}=$ Positive Affect, NA = Negative Affect, SES = Self-esteem, Cig. = Cigarettes, Sleep = sleeping problems, Ph. A. = Physical Activity, Analg. $=$ Analgesics, TV = Television

**. Correlation is significant at the 0.01 level (2-tailed).

*. Correlation is significant at the 0.05 level (2-tailed).

Table 3: Patient group. Correlation coefficients (Pearson's r) between Positive affect, Negative affect, Self-esteem, energy, stress, cigarettes, sleeping problems, physical activity, analgesics and television.

\begin{tabular}{|l|l|}
\hline Predictor variable & Standardized Beta ( $\beta$ ) \\
\hline Stress & -0.14 \\
\hline Energy & 0.16 \\
\hline Cigarettes/day & -0.07 \\
\hline Pain & -0.10 \\
\hline Analgesics & $-0.29^{\star}$ \\
\hline Television hours/day & -0.07 \\
\hline Sleeping problems & 0.75 \\
\hline Self-esteem & $0.49^{* *}$ \\
\hline
\end{tabular}

Table 4: Patient group. Standardized weights from multiple regression analysis with affective mood as dependent variable and stress, energy, number of cigarettes/day, pain, analgesics, television, sleeping problems and self-esteem as independent variables ${ }^{*} p<0.05,{ }^{* *} p<0.01$ needs to be added.

\begin{tabular}{|l|l|}
\hline Predictor variable & Standardized Beta ( $\beta$ ) \\
\hline Stress & $-0.40^{\text {*** }}$ \\
\hline Energy & $0.21^{* *}$ \\
\hline Cigarettes/day & 0.03 \\
\hline Pain & -0.13 \\
\hline Analgesics & 0.10 \\
\hline Television hours/day & 0.04 \\
\hline Sleeping problems & -0.05 \\
\hline Self-esteem & $0.41^{* *+}$ \\
\hline
\end{tabular}

Table 5: Healthy volunteers. Standardized weights from multiple regression analysis with affective mood as dependent variable and stress, energy, number of cigarettes/day, pain, analgesics, television, sleep and self-esteem as independent variables ${ }^{* *} p<0.01,{ }^{* * *} p<0.001$

praxis as a way of developing the treatment of this patient group.

Overall, we expected to see more NA and less PA among the patient group as well as more stress and less self-esteem. We also expected to observe different predisposing and similar protective factors and to be able to find key attributes in order to find patients at risk.

Our results clarified some issues of the emotional disturbances among the patient group. They showed evidence of differences between the groups in self-rated stress, analgesics and self-rated energy. In the group of healthy controls stress was counter predictive for positive affective mood, but this could not be shown for the patient group. Not surprisingly, analgesics was found to be counter-predictive for positive Affective Mood in the patient group, but not for the healthy controls. Analgesics was interpreted as a predisposing factor for the Affective Deaf Syndrome (ADS) and identified as a key attribute for the patients at risk. This will be a factor to consider in the treatment aimed at overcoming the affective problems of the patients. Self-rated energy was predictive for positive mood and thus helpful for the healthy controls but not for the patients. Healthy controls experienced energy, but patients did not. This circumstance begs the question: Why was the experience of energy not predictive for positive affective mood in the patient group as it was in the control group? Was it because the analgesics block this energy? The lesser experience of energy in the patient group must be taken seriously and be considered as central both in the prevention of emotional disturbances and in the treatment of the patients' disorders. One reason for the lack of energy among the patients might be due to the psychiatric conditions in the patient group.

Self-esteem was found to predict positive affective mood for both groups although the patients had less self-esteem. The fact that self-esteem is predictive for positive Affective mood has earlier been demonstrated (Archer, Adolfsson \& Karlsson, 2008). We have clinically observed that many of the deaf and hard-of-hearing patients have very little support from their families. This may be due to communication difficulties. As the results show the communication problems were huge. Contributing were also psychiatric problems with $42 \%$ of the patients fulfilling at least two psychiatric diagnoses. Depression was often combined with anxiety disorder and/or with trauma and stress-related disorders. Living and growing up without full means of communication with the family is a great handicap because usually this is the place for learning to understand oneself, other persons, and society. Many of the families are having problems in different areas and this might be a contributing factor to the Affective Deaf Syndrome. It is interesting to notice that in the study of Black \& Glickman they found that $75 \%$ of deaf individuals fell into the non-fluent range of communication in American Sign Language (Black \& Glickman, 2006). They also found a broader range of diagnoses than in past studies. Compared with hearing patients in the same hospital, deaf patients were more likely to be diagnosed with a mood, anxiety, personality, or developmental disorder. They also found that psychosocial functioning of the deaf patients was generally similar to hearing psychiatric patients.

Considering the pattern of our findings among the patient group compared to healthy controls, it is concluded that all information regarding the differences between patients and healthy controls is useful for designing intervention. The fairly good self-esteem may be a good starting ground for psychiatric treatment. It helps the patients to interact with the intervention program and makes them open enough to integrate the treatment into their lives. As we have seen, the use of analgesics is a problem for the patient group and make them at risk for less affective mood. Analgesics may thus be seen as a key attribute for risk and must be taken into consideration when treating the patients' 
psychiatric illness. Earlier studies have shown conflicting results on substance use among deaf people compared to hearing individuals. Black and Glickman (2006) reports a total of substance disorders at $33 \%$ in their study and refers to a report by Rainer and Altshuler (1966) where one third of approximately 4,000 patients were presented with alcohol psychoses, but none of the deaf patients received the diagnoses. On the other hand, Pollard (1994) found that the deaf sample had a higher percentage of substance abuse (17\%) compared to the hearing sample (15\%). In our patient group only two persons were considered having this diagnose, however the praxis in our clinic is that patients with abuse problems are sent to the toxicological unit for treatment, and only comes to our unit when they no longer fulfil the criteria for abuse disorder. It may be considered further why our results indicate that analgesics and not pain is counter-predictive for positive affective mood in the patient group.

Autism spectrum disorder (ASD) was observed in our material in $21 \%$ of the patient group. Difficulties in social communication and interaction are diagnostic for ASD. While language difficulties are a core characteristic of autism, as with the disorder itself, linguistic functioning can be highly variable within those on the spectrum. Verbal and nonverbal communications are vital for the formation of social interactions. Thus, insights regarding the nature of linguistic difficulties in ADS also may facilitate the further understanding of basis of this condition.

At the heart of the Affective Deaf Syndrome remains the patients' problems communicating their emotional difficulties. On the basis of present findings, it appears that the patients have the capability to use the self-evaluation questionnaire although this needs to be done in cooperation of with sign language interpreters trained to deal with the issues and concerns that exist in mental health settings.

\section{Limitations}

The special situation of this patient-group implies that the number of individuals available for participation was limited. Nevertheless, the findings seem robust. We suggest that repeated self-evaluations over a period of treatment may add to further knowledge of the Affective Deaf Syndrome. One reason for our opinion is that the patients felt at ease with the results when individually revealed to them after the end of the study during their regularly meetings with their psychiatrist. They also expressed that they felt co-responsible for the treatment and this situation has rendered an experience of self-control by the patients and a subjective feeling of contributing to their own progress.

\section{Conclusions}

The present study emphasizes deaf and hard-or-hearing psychiatric patients' problems of communicating their emotional difficulties. The questionnaire used in the study contributed to a structured assessment of affective mood and mental distress. As a result, we gained knowledge in understanding the Affective Deaf Syndrome. Firstly, the striking communication problems showed a high rate of non-fluent sign communication (86\%) within the families of the patients and a poor knowledge of the Swedish language by the patients. Secondly, self-esteem was found to predict positive affective mood for both groups although the patients had less self-esteem. Positive self-esteem is identified as a protective factor. Thirdly, the result indicated differences between patients and a healthy control groups in self-rated stress, analgesics and self-rated energy. Analgesics was interpreted as a predisposing factor for the Affective Deaf Syndrome (ADS) and identified as a key attribute for the patients at risk. Stress was positively related to sleep disturbance and analgesics.

\section{Acknowledgements}

Psychologists Johannes Einestam and Vera Lundborg, specialist nurse Anette Ohlson, occupational therapist Pernilla Malmros and social counselor Eva Lundholm helped in collecting the data often in cooperation with sign interpreters.

\section{References}

1. Hoyt MF, Siegelman EY, Schlesinger HS (1981) Special issues regarding psychotherapy with the Deaf. American Journal of Psychiatry 138: 807-810.

2. Philips BA (1996) Bringing culture to the forefront: Formulating diagnostic impressions of Deaf and and-of-hearing people at times of medical crisis. Professional Psychology: Research and Practice 27: 137-144.

3. Williams CR, Abeles N (2004) Issues and Implications of Deaf Culture in Therapy. Professional Psychology: Research and Practice 35: 643-648.

4. McCay V, Miller C (2001) Interpreting in Mental Health Settings: Issues and Concerns. American Annals of the Deaf 145: 429-434.

5. Endler NS, Parker JDA (1990) Multidimensional assessment of coping: a critical evaluation. Journal of Personality and Social Psychology 58: 844-854.

6. De Ridder D, Schreurs K (1996) Coping, social support and chronic disease: a research agenda. Psychology, Health \& Medicine 1: 71-82

7. Zeidner M, Saklofske D (1996) Adaptive and maladaptive coping. In M Zeidner and N. S. Endler (Eds.) Handbook of Coping: Theory, Research and Applications. (pp 505-531). New York: John Wiely.

8. Endler NS, Kocovski NL, Macrodimitris SD (2001) Coping, efficacy, and perceived control in acute vs. chronic illness. Personality and Individual Differences 30: 617-625.

9. Bisschop MI, Kriegsman DMW, Beekman ATF, Deeg DJH (2004) Chronic diseases and depression: the modifying role of psychosocial resources. Social Science \& Medicine 59: 721-733.

10. Teasdale JD (1988) Cognitive vulnerability to persistent depression. Cognition and Emotion 2: 247-274.

11. Butler AL, Hokanson JE, Flynn HA (1994) A comparison of self-esteem liability and low trait self-esteem as vulnerability markers for depression. Journal of Personality and Social Psychology 66: 166-177.

12. Roberts JE, Kassel JD, Gotlib IH (1995) Level and stability of self-esteem as predictors of depressive symptoms. Personality and Individual Differences 19 : 217-224.

13. Strauman Rosenberg M (1965) Society and the adolescent self-image. (Princeton University Press: Princeton, N.J.).

14. Kernis $\mathrm{MH}$, Whisenhunt $\mathrm{CR}$, Waschull SB, Greenier KD, BerryA J et al. (1998) Multiple facets of self- esteem and their relations to depressive symptoms. Personality and Social Psychology Bulletin 24: 657-668.

15. Frank E, De Raedt R, (2007) Self-esteem reconsidered: unstable self-esteem outperforms level of self-esteem as vulnerability marker for depression. Behaviour Research and Therapy 45: 1531-1541.

16. Palomo T, Beninger RJ, Kostrzewa RM, Archer T (2004) Gene-environment interplay in affect and dementia: emotional modulation of cognitive expression in personal out- come. Neurotoxicity Research 6: 159-173.

17. Jones F, Bright J (2001) Stress. Myth, theory and Research. Essex: Pearson Education Limited.

18. Clark A, Watson LA (1988) Mood and the mundane: relations between daily life events and self-reported mood. Journal of Personality and Social Psychology 54: 296-308.

19. Clark LA, Watson D (1991) Tripartite model of anxiety and depression: Psychometric evidence and taxonomic implications. Journal of Abnormal Psychology 100: 316-336.

20. Tellegen A (1993. Folk concepts and psychological concept of personality and personality disorder. Psychological Inquiry 4: 122-130.

21. Aldwin CM (1994) Stress, coping and development: An integrative perspective New York: Guilford.

22. Melvin GA, Molly GN (2000). Some psychometric properties of Positive and Negative Affect Schedule among Austrian youth. Psychological Reports 86: 
Citation: Zöller MET, Archer T (2015) Emotional Disturbances Expressed by Deaf Patients: Affective Deaf Syndrome. Clin Exp Psychol 2: 109. doi:10.4172/2471-2701.1000109

Page 7 of 8

$1209-1212$.

23. Watson D, Pennebaker JW, Folger R (1986) Beyond negative affectivity: measuring stress and satisfaction in the workplace. Journal of Organizational Behavior Management 8: 141-157.

24. Lyubomirksy S, King L, Diener E (2005) The benefits of frequent positive affect: Does happiness lead to success? Psychological Bulletin 6: 803-855.

25. Watson D, Clark LA, Tellegen A (1988a) Development and validation of brief measures of positive and negative affect: the PANAS scales. Journal of Personality and Social Psychology 54; 1063-1070.

26. Watson D, Carey LA, Carey G (1988b) Positive and negative affectivity and their relation to anxiety and depressive disorders. Journal of Abnormal Psychology 97: 346-353.

27. Spector PE, O'Connell BJ (1994) The contribution of personality traits, negative affectivity, locus of control and Type A to the subsequent reports of job stressors and job strains. Journal of Occupational and Organisational Psychology 67: $1-11$.

28. McCrae RR, Costa PT (1987) Validation of the five-factor model of personality across instruments and observers. Journal of Personality and Social Psychology 1: 81-90.

29. Watson D, Clark L (1984) Negative affectivity: the disposition to experience aversive negative states. Psychological Bulletin 96: 465-490.

30. Varg N (1997) The influence of negative affect upon responses to questionnaires. Stockholm: Stockholm University Reports.

31. Costa PTJ, McCrae RR (1980) Influence of extroversion and neuroticism on subjective well-being: happy unhappy people. Journal of Personality and Social Psychology 38: 668-687.

32. Watson D, Clark L (1984) Negative affectivity: the disposition to experience aversive negative states. Psychological Bulletin 96: 465-490.

33. Watson, D, Pennebaker JW (1989) Health complains, stress, and distress: exploring the central role of negative affectivity. Psychological Review 96: 234254

34. Garcia D, MacDonald S, Archer T (2015) Two different approaches to the affective profiles model: median splits (variable-oriented) and cluster analysis (person-oriented). PeerJ 3:e1380.

35. Agerström J, Möller K, Archer T (2006) Influence of affective personality and dilemma content on moral reasoning: effect of gender. Social Behavior and Personality 34: 1259-1276.

36. Karlsson E, Archer T (2007) Relationship between personality characteristics and affect: gender and affective personality. Individual Differences Research 5: 44-58.

37. Palomo T, Kostrzewa RM, Beninger RJ, Archer T (2007) Treatment consideration and manifest complexity in comorbid neuropsychiatric disorders. Neurotoxicity Research 12: 43-60.

38. Schütz E, Garcia D, Archer T (2014) Affective state, stress and Type A-personality as a function of gender and affective profiles. International Journal of Research Studies in psychology 3: 51-64.

39. Zöller ME, Karlsson E, Archer T (2009) Self-rated affect among adults presenting psychiatric diagnosis. Individual Differences Research 7: 14-28.

40. Zöller M, Archer T (2009) Predicting stress in male and female psychiatric patients and healthy volunteers. Social Behavior and Personality 37: 10811094.

41. Zöller MT (1997) Neurofibromatosis I. Psychiatric and somatic aspects: A 12year follow-up of adult patients in Sweden. Göteborg University, Göteborg.

42. Zöller M, Rembeck B, Bäckman L (1997) Neuropsychological deficits in adults with neurofibromatosis type 1. Acta neurologica Scandinavica 95: 225-232.

43. Coccaro EF (1989) Central serotonin and impulsive aggression. The British Journal of Psychiatry 155: 52-62.

44. Peirson AR, Heuchart JW (2000) Correlations for serotonin levels and measures of mood in a nonclinical sample. Psychological Reports 87: 707-716.

45. Tranter R, Healy H, Cattell D (2002) Functional effects of agents differentially selective to noradrenergic or serotonergic systems. Psychological Medicine 32 : 517-524.
46. Verkes RJ, Hengeveld MW, van der Mast RC, Fekkes D, van Kempen GMJ (1998) Mood correlates with blood serotonin, but not with glucose measures in patients with recurrent suicide behavior. Psychiatry Research 80: 239-248.

47. McFarlin DB, Blascovich J (1981) Effects of self-esteem and performance feedback on future affective preferences and cognitive expectations. Journal of Personality and Social Psychology 40: 521-531.

48. Baumeister RF, Tice DM (1985) Self-esteem and responses to success and failure: subsequent performance and intrinsic motivation. Journal of Personality 53: $450-467$.

49. Bensink GW, Godbey KL, Marshall MJ, Yarandi HN (1992) Institutionalized elderly: relaxation, locus of control, self- esteem. Journal of gerontological nursing 18: 30-36.

50. Conn VS, Taylor SG, Hayes V (1992) Social support, self- esteem, and selfcare after myocardial infarction. Health Values 16: 25-31.

51. Baumeister RF, Heatherton TF, Tice DM (1993) When ego threats lead to self-regulation failure: negative consequences of high self-esteem. Journal of Personality and Social Psychology 64: 141-156.

52. Christian A (1993) The relationship between women's symptoms of endometriosis and self-esteem. Journal of obstetric, gynecologic and neonatal nursing 22: 370-376.

53. Cannella D T L, Lobel M, Glass P, Lokshina I, Graham JE (2007) Factors associated with depressed mood in chronic pain patients: the role of intrapersonal coping resources. The Journal of Pain 8: 256-262.

54. Lakey B, Scoboria A (2005) The relative contribution of trait and social influences to the links among perceived social support, affect and self-esteem. Journal of Personality 73 : 361-388.

55. Nicassio PM, Mendlowitz DR, Fussell JJ, Petras L (1985) The phenomenology of pre-sleep state: the development of pre-sleep arousal scale. Behaviour Research and Therapy 23: 263-271.

56. Ezquiaga E, Garcia A, Pallares T, Bravo MF (1999) Psychosocial predictors of outcome in major depression: a prospective 12-month study. Journal of affective disorders 52: 209-216.

57. Gureje OC, Harvey C, Herrman H (2004) Self-esteem in patients who have recovered from psychosis: profile and relationship to quality of life. Australian \& New Zealand Journal of Psychiatry 38: 334-338.

58. Muhlenkamp AF, Sayles JA(1986) Self-esteem, social support, and positive health practices. Nursing research $35: 334-338$

59. Stern M, Alvarez SL (1992) Pregnant and parenting adolescents: a comparative analysis on style of coping, self-image, and family environment. Journal of Adolescent Research 7: 469-493.

60. Baumeister RF, Bratslavsky E, Finenauer C, Vohs K (2001) Bad is stronger than good. Review of General Psychology 5: 323-370.

61. Taylor SE, Brown JD (1988) Illusion and well-being: a social psychological perspective on mental health. Psychological Bulletin 103: 193-210.

62. Scheier MF, Carver CS (1992) Effects of optimism on psychological well-being: theoretical overview and empirical update. Cognitive Therapy and Research 16 : 210-228.

63. Taylor SE, Kemeny M E, Aspinwall LG, Schneider SG, Rodriguez R, et al. (1992) Optimism, coping, psycho-logical distress, and high-risk sexual behaviour among men at risk for acquired immunodeficiency syndrome (AIDS). Journal of Personality and Social Psychology 63: 460-473.

64. Scheier MF, Carver CS, Bridges MW (1994) Distinguishing optimism from neuroticism (and trait anxiety, self-mastery, and self-esteem): A reevaluation of the Life Orientation Test. Journal of Personality and Social Psychology 67: 10631078.

65. Bjorck JP, Hopp PD, Jones LW (1999) Prostate cancer and emotiona functioning: effects of mental adjustment, optimism, and appraisal. Journal of Psychosocial Oncology 17: 71-85

66. Scheier MF, Carver CS (1987) Dispositional optimism and physical well-being the influence of generalized outcome expectancies on health. Journal of Personality 55: 169-210.

67. Scheier M F, Weintraub JK, Carver CS (1986) Coping with stress: divergent strategies of optimists and pessimists. Journal of Personality and Social Psychology 51: 1257-1264. 
Citation: Zöller MET, Archer T (2015) Emotional Disturbances Expressed by Deaf Patients: Affective Deaf Syndrome. Clin Exp Psychol 2: 109. doi:10.4172/2471-2701.1000109

68. Aspinwall LG, Taylor SE (1992). Modeling cognitive adaptation: a longitudinal investigation of the impact of individual differences and coping on college adjustment and performance. Journal of Personality and Social Psychology 63: 989-1003.

69. Friedman LC, Nelson DV, Baer PE, Lane M, Smith FE, et al. (1992) The relationship of dispositional optimism, daily life stress, and domestic environment to coping methods used by cancer patients. Journal of Behavioral Medicine 15: 127-141.

70. Segerström SC (2005) Optimism and immunity: Do positive thoughts always lead to positive effects? Brain, Behavior, and Immunity 19: 195-200.

71. Grinker R Vernon M Mindel E, Rothstein DA, Easton H, et al. (1969) Psychiatric diagnosis, therapy and research on the psychotic deaf. Washington, DC Department of Health, Education and Welfare (Research Grant \#RD2407-S from the division of Research and Demonstration Grants, social and Rehabilitation Service).

72. Black PA, Glickman NS (2006) Demographics, psychiatric Diagnoses, and Other Characteristics of North American Deaf and Hard-of Hearing Inpatients. Journal of Deaf Studies and Deaf Education 11: 303-321.

73. Pollard RQ (1994) Public mental health service and diagnostic trends regarding individuals who are deaf or hard-of-hearing. Rehabilitation Psychology 39: 147160

74. Fellinger J, Holzinger D, Dobner U, Gerich J, Lehner R, et al. (2005) An innovative and reliable way of measuring health-related quality of life and mental distress in the deaf community. Social psychiatry and psychiatric epidemiology 40: 245-250.

75. Schütz E, Sailer U, Nima AA, Rosenberg P, Andersson-Arntén AC, et al. (2013) The affective profiles in the USA: happiness, depression, life satisfaction, and happiness-increasing strategies. PeerJ 1:e156.

76. Kjellerg A, Ivanowski S (1989) Stress/energiformuläret: utveckling av en metod för skattning av sinnesstämning i arbetet [The stress/energy questionnaire: development of a method for assessing mood at the work place]. Solna: Enheten för psykofysiologi, Arbetsmiljöinstitutet (Vol 26).

77. Archer T, Adolfsson B, Karlsson E (2008) Affective personality as cognitiveemotional presymptom profiles regulatory for self-reported health predispositions. Neurotoxicity Research 14: 21-44.
78. American Psychiatric Association diagnostic and Statistical Manual of Mental Disorders, DSM-5. Diagnostic and Statistical Manual of mental disorders, 2013.

79. Kjellberg A, Bohlin B (1974) Self-reported arousal: further development of a multifactorial inventory. Scandinavian Journal of Psychology 15: 285-292.

80. Morrison DN, McGee R, Stanton WR (1992) Sleep problems in adolescence. Journal of the American Academy of Child and Adolescent Psychiatry 31: 9499.

81. Nowlis V (1965) Research with the Mood Adjective Checklist, In: Affect, Cognition, and Personality: Empirical studies (Tomkins SS, Ed.) (Springer: Oxford), pp 464486.

82. Palomo T, Beninger RJ, Kostrzewa RM, Archer T (2008) Affective status in relation to impulsive, motor and motivational symptoms: personality, development and physical exercise. Neurotoxicity Research 14: 151-168.

83. Perris C, Eisemann M, Eriksson U, von Knorring L, Perris H (1979) Variations in selfassessment of personality characteristics in depressed patients with specia reference to aspects of aggression. Psyciatrica Clinica 209: 209-215.

84. Rainer JD, Altshuler KZ (1966) Comprehensive mental health services for the deaf. New York Psychiatric Institute, Columbia University.

85. Sjöberg L, Svensson E, Persson LO (1979) The measurement of mood. The Scandinavian Journal of Psychology 20: 1-18.

86. Socialstyrelsen (2011) Internationell statistisk klassifikation av sjukdomar och relaterade hälsoproblem Systematisk förteckning Svensk version (ICD-10 SE). The ICD-10 classification of mental and behavioural disorders: clinical descriptions and diagnostic guidelines. Geneva: WHO, 1992.

87. Strauman TJ, Kolden GG (1997) The self in depression: Research trends and clinical implications. In Session: Psychotherapy in Practice 3: 5-21.

88. Watson D, Clark LA, Tellegen A (1988a) Development and validation of brief measures of positive and negative affect: the PANAS scales. Journal of Personality and Social Psychology 54; 1063-1070.

89. Watson D, Carey LA, Carey G (1988b) Positive and negative affectivity and their relation to anxiety and depressive disorders. Journal of Abnormal Psychology 97: 346-353.

90. Wilson K, Gullone E, Moss S (1998) The Youth Version of the Positive and Negative Affect Schedule: a psychometric validation. Behaviour Change 15: 187193. 